\title{
Research on the Compound Process of Hot Stamping and Heat Treatment for Duralumin Alloy Fairing with Large Aspect Ratio: Experiment and modeling
}

\author{
Lingzhi $\mathrm{Xu}^{1}$, Lihua Zhan ${ }^{1,2,3, *}$, Minghui Huang ${ }^{1}$, Liang Guo ${ }^{1}$,Ziyao $\mathrm{Ma}^{1}$ \\ ${ }^{1}$ School of Mechanical and Electrical Engineering, Central South University, Changsha 410083, China \\ 2State Key Laboratory of High-Performance Complex Manufacturing, Central South University, Changsha 410083, China \\ ${ }^{3}$ Nonferrous Metal Oriented Advanced Structural Materials and Manufacturing Cooperative Innovation Center, Central South \\ University, Changsha, 410083, China
}

\begin{abstract}
The compound process of hot stamping and solution quenching heat treatment $\left(\mathrm{HFQ}{ }^{\circledR}\right)$ was utilized to fabricate hard aluminium fairing of high aspect ratio. A simulation model was established by MSC.Marc to optimize the shape and size of the blamk as well as the effects of process parameters, namely, initial temperature, stamping speed, blank holder force (BHF), on extreme final temperature and thickness distribution of formed component were investigated. The reliability of finite element simulation was proved by the hot stamping experiments with selfdesigned moulds under the optimize process parameters achieved by simulation results. The results indicated that the optimized blank is well deformed without flange wrinkle and broken round; the maximum cooling rate in quenching can inhibite the precipitation when the initial temperature ranges from 350 to $450^{\circ} \mathrm{C}$; BHF effects dominated on thickness distribution and $10 \mathrm{KN}$ is the most reasonable value under the studied condition while the optimum stamping speed is $100 \mathrm{~mm} \bullet \mathrm{s}^{-1}$. Compared with the thickness of the stamping trials and numerical simulation, the deviation is less than $3.6 \%$. Furthermore, The desired mechanical property is achieved without significant inhomogeneity.
\end{abstract}

Key word: Aluminium, Finite element method, Hot stamping, Manufacturing process

\section{Introduction}

Nowadays, lightweighting is one of the most importance development directions on the aerospace industries. Therefore, the lightweight and high strength characteristics of duralumin alloy, represented by the Al$\mathrm{Cu}-\mathrm{Mg}$ alloy in 2XXX series, determine its application prospects in aerospace and other industries[1].The duralumin alloy is mainly characterized by low density, high specific strength and good heat resistance, and its mechanical properties can be significantly strengthened by solution and aging. Such wonderful performance has making those aluminum alloy one of the best materials for manufacturing load bearing structures in aerospace vehicles.

Stamping is a typical sheet metal forming process. In such process, the sheet blank undergoes a large tensioncompression stress due to punching into the deep die, resulting in a great plastic deformation[2].Stamping process is widely used in manufacturing thin-walled components in cylindrical, box, staircase, cone, sphere and other complex shapes. However, the components of aerospace vehicles are not only have complex structures, but also require high forming accuracy and good mechanical performance. It is very difficult to achieve desired shape and performance requirement by the tradition cold forming process through single forming, some of which are unable to fabricate by cold forming, especially for aluminum alloys. For example, fairing, an important structural on a launch vehicle[3], is a complicated structure with streamlined curved surfaces which currently manufacturing by cold forming process. But the production efficiency and the finished product rate are relatively low, makes it difficult to meet the mass production needs. Some studies have shown that the duralumin alloy will produce dynamic recovery and dynamic recrystallization softening during the deformation under the elevated temperature, which will weaken or eliminate the work hardening caused during the deformation process[4]. Therefore, the hot forming can improve the plasticity of the material, reduce the flow stress and overcome the forming defects of duralumin alloy at room temperature. 
According to recent researchs, many advanced forming processes such as hot stamping, superplastic forming, differential temperature drawing, etc.[5-6] show unique advantages for forming complex thinwalled components. DMFinch et al.[7] conducted theoretical and experimental studies on warm forming of aluminum alloy sheets. The results show that the temperature and blank holder force have important influence on the forming of aluminum alloy box and tube. Under the studied temperature, the formability of 2020-T4, 7075-T6 and other aluminum alloy sheets have been greatly improved. MJPainter et al.[8] found that the stamping limit of $\mathrm{Al}-2 \mathrm{Mg}$ aluminum alloy cylindrical parts increases with the increase of forming temperature and stamping speed, which means that the formability of $\mathrm{Al}-2 \mathrm{Mg}$ aluminum alloy cylindrical parts increases greatly compared with normal temperature. Zhenghua Guo[9] has conducted the warm forming experimental on the 5182 aluminum cylindrical shape (diameter $40 \mathrm{~mm}$ ), and found that when forming temperature increase from $100{ }^{\circ} \mathrm{C}$ to $250{ }^{\circ} \mathrm{C}$ without lubrication, the ultimate stamping limit increase from $4 \mathrm{~mm}$ to $10.5 \mathrm{~mm}$. And with the Grafo LN-1169 lubricant, the ultimate stamping limit could increase to $15.5 \mathrm{~mm}$. Above explained that the formability of the 5182 aluminum alloy sheet increased dramatically with increasing temperature and greater lubrication. Lei $\mathrm{Fu}$ [10-12] utilized HFQ process[13] to AA6111 aluminum alloy, but the properties of formed components has not been studied. Wenke Li [14] studied the hot stamping process on fabricating U-shaped parts of 6061 aluminum alloy through the comparison between finite element simulation and hot stamping experiment, and found that the hot stamping process can significantly improve the forming quality under the premise of basically no weakened performance. For the 2XXX series of duralumin alloy, there is few research on the performance control of thermoplastic formation process. Therefore, in this paper, 2A12 aluminum alloy thinwalled fairing with large aspect ratio that widely used in aerospace vehicle are taken as the object of this study to conduct a feasibility study on the compound process of hot stamping and quenching heat treatment, which known as $\mathrm{HFQ}{ }^{\circledR}$ [15]. This process are considered to be an integrated high-efficiency and short-flow method to achieve the shape and performance of the component. The material were heated to $500{ }^{\circ} \mathrm{C}$ and hold in the solution temperature for $40 \mathrm{~min}$, which in the state of low deformation resistance and good plasticity, and then be quickly put into the mould for heat stamping. The mould is equipped with sink, which can introduce cooling water to realize the rapid quenching of components. After quenching, the component is pressured in specific shape and be further aging heat treatment. The studied compound process is more simple than the traditional cold forming process that consists of multiple forming, intermediate annealing and solution-quenching-aging. Moreover, this process effectively prevent the loss of forming accuracy in the subsequent high temperature solution-quenching due to the quenching residual stress. The research work is of great significance for improving the precision and efficiency of the forming of duralumin alloy components and expanding its application in aerospace and other fields.

\section{The establishment of simulation model}

It has been shown in the existing literature that the ultimate aspect ratio of a qualified part formed by cold drawing is 0.64 . In this paper, the studied duralumin alloy thin-walled fairing fabricated by hot stamping has an aspect ratio of 1.2, and consists mainly of arcuate surfaces, including the die radius of R10, the punch radius of R20 and the circular arc of R90. The geometry is modeled through the $3 \mathrm{D}$ software Pro / E which is shown in Fig. 1, and then imported into MSC.Marc software to build the whole simulation model.

Fig. 2 shows the finite element model followed by the punch, blank holder die, blank and die from top to bottom. A certain amount of sheet metal flange were left for blank holder process. In order to improve the efficiency of simulation, double-cavity symmetrical pressing method was used. A 1/4 model was established and the number of set-up units was 3690, a grid redivision was performed every five time steps, and the sheet was meshed using 3D-Shell No. 75.

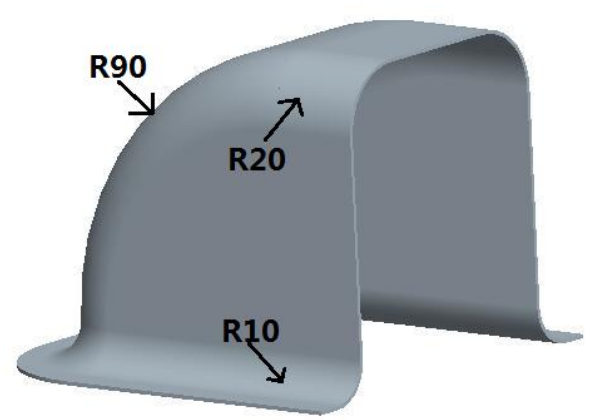

Fig.1. Three-dimensional modeling of the fairing

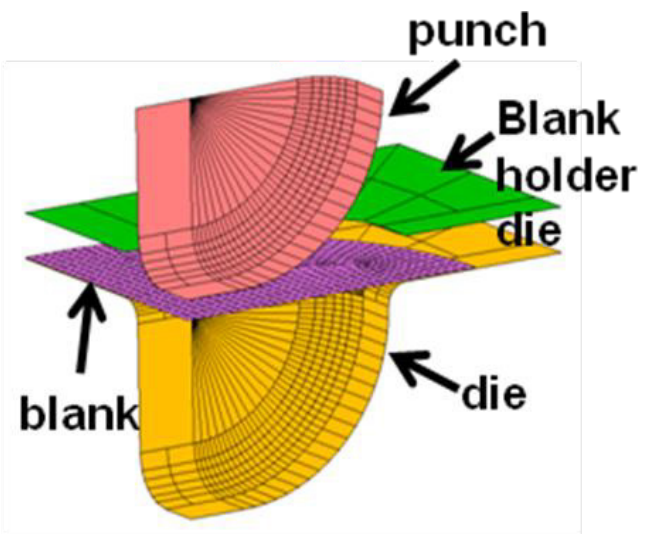

Fig.2. Finite element model

In finite element simulation, the exact definition of material properties has a vital impact on the validity and correctness of simulation results. The elastic-plastic isotropic model is adopted, which has a density of $2.78 \mathrm{E}-9 \mathrm{t} \cdot \mathrm{mm}^{-3}$, an elastic modulus of $72 \mathrm{GPa}$ and a 
Poisson's ratio of 0.31 . Since the numerical simulation of hot stamping is thermo-mechanical coupling, it is necessary to set the thermal physical parameters of the material, namely, the thermal conductivity is $117.2 \mathrm{~W} \cdot \mathrm{m}^{-}$ ${ }^{1} \cdot \mathrm{K}^{-1}$, the specific heat capacities at different temperatures and the average coefficient of linear expansion as shown in Table 1.

Table 1. The thermal physical parameters of 2A12 duralumin alloy

\begin{tabular}{cccc}
\hline $\begin{array}{c}\text { Temper } \\
\text { ature } \\
\mathrm{T} /{ }^{\circ} \mathrm{C}\end{array}$ & $\begin{array}{c}\text { specific } \\
\text { heat } \\
\mathrm{c} / \mathrm{J} \cdot(\mathrm{Kg} \cdot \\
\mathrm{K})^{-1}\end{array}$ & $\begin{array}{c}\text { temperature } \\
\text { interval } \mathrm{T} /{ }^{\circ} \mathrm{C}\end{array}$ & $\begin{array}{c}\text { average coefficient of } \\
\text { linear expansion } \\
\mathrm{a}_{\mathrm{l}} / 10^{-6} \cdot \mathrm{K}^{-1}\end{array}$ \\
\hline 100 & 921 & $20 \sim 100$ & 22.7 \\
200 & 1047 & $20 \sim 200$ & 23.8 \\
300 & 1130 & $20 \sim 300$ & 24.7 \\
400 & 1172 & $20 \sim 400$ & - \\
\hline
\end{tabular}

The true stress-strain relationship at different strain rates and temperatures during the hot stamping process is described by the Z-parameter thermo-hydro-mechanical constitutive model (1), taking into account the effects of temperature changes.

$$
\left\{\begin{array}{l}
\sigma=\frac{1}{\alpha} \ln \left\{\left(\frac{Z}{A}\right)^{1 / n}+\left[\left(\frac{Z}{A}\right)^{2 / n}+1\right]^{1 / 2}\right\} \\
Z=\exp \left(\frac{Q}{R T}\right)
\end{array}\right.
$$

$\alpha=0.026-0.018 \varepsilon-0.028 \varepsilon^{2}+0.081 \varepsilon^{3}$,

$n=9.31-28.25 \varepsilon+83.07 \varepsilon^{2}-84.38 \varepsilon^{3}$,

$Q=230.67-214.59 \varepsilon+347.42 \varepsilon^{2}-289.14 \varepsilon^{3}$,

$\ln A=34.78-9.58 \varepsilon-114.13 \varepsilon^{2}+201.77 \varepsilon^{3}$ 。

According to the definition principle of contact body, the sheet is defined as deformable contact body, and the punch, die and blank holder are defined as rigid contact body, with the friction coefficient of 0.1 . The heat transfer coefficient between the sheet metal and air can be ignored in simulation for its much smaller than that between the sheet metal and the mould during the hot stamping process. In addition, only the influence of the gap on the heat transfer coefficient is considered to simplify the calculation. The contact heat transfer coefficient between the sheet metal and the mould is set to $0.7 \mathrm{~kW} \cdot\left(\mathrm{m} 2 \cdot{ }^{\circ} \mathrm{C}\right)^{-1}$ and the mould initial temperature is set to a constant temperature $25^{\circ} \mathrm{C}$.

\section{Simulation results and analysis}

For the hot stamping process, the shape and size of the blank is an important factor affecting the forming accuracy and performance of the component. The shape of the blank has a significant effect on the flow of the sheet material during forming. A large blank will not only waste material, but also increase the chances of wrinkling and rupture; while a small blank will cause excessive sheeting thinning, leads to the loss of forming accuracy. Therefore, a reasonable blank shape and size can help eliminate the defects of forming process.
The results of the $1 / 4$ model simulation show that the rectangular corner has a significant impediment to the flow of the sheet material during the forming of the rectangular blank, resulting in the uneven distribution of the part thickness and the wrinkling at the flange. But with rounded corners as R90's blank shape, the fracture of the forming part is improved, and the flow of sheet material was more reasonable. The final shape of the smallest optimized blank size is $170 \mathrm{~mm} \times 150 \mathrm{~mm}$, whose specific size shown in Fig. 3.

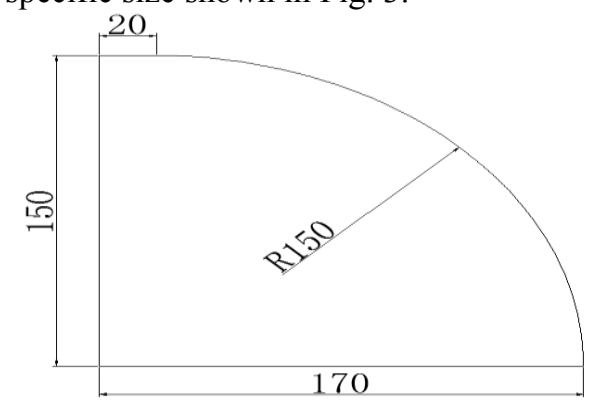

Fig.3. Specific size of quarter rounded blank $(\mathrm{mm})$

Based on the above blank, a simulation analysis under the die gap of $1.3 \mathrm{~mm}$, the die radius of $10 \mathrm{~mm}$, the forming temperature of $450{ }^{\circ} \mathrm{C}$, the stamping speed of $100 \mathrm{~mm} \cdot \mathrm{s}^{-1}$, the blank holder force of $10 \mathrm{KN}$, the dwell time of $6 \mathrm{~s}$, the friction coefficient of 0.1 was carried out as an example to obtain the overall thickness distribution of the formed component, shown in Fig. 4. The maximum thinning ratio is usually used as an important index to evaluate the forming quality of the formed component, and the value is generally not more than $30 \%$ [16]. As for the studied 2A12 aluminum alloy sheet with the thickness of $1.2 \mathrm{~mm}$, the minimum thickness of the formed component required to be thicker than $0.84 \mathrm{~mm}$.

It can be seen from Fig. 4 (b) that under the above simulation paremeters, the minimum thickness of formed component is $0.867 \mathrm{~mm}$, and the maximum thinning rate is calculated to be $27.7 \%$, that is, no rupture failure occurs. As the component is completely symmetrical, the date of thickness of cross-section along the transverse and longitudinal path were obtained and the thicknessexpansion distance curve is shown in Fig.4(b).

As can be seen from the Fig.4(b), the transverse and longitudinal expansion distances increase from $150 \mathrm{~mm} \times$

$170 \mathrm{~mm}$ to $174.8 \mathrm{~mm} \times 210.6 \mathrm{~mm}$, with an increase of $16.5 \%$ and $23.9 \%$, respectively, and the thickness of the point on the transverse path is generally lower than that of the longitudinal one. The thickness of the selected points on the transverse section gradually increases with the expansion distance, and the maximum value is 1.49 $\mathrm{mm}$ at the flange due to the superposition of the flanges. The thickness of the selected points on the longitudinal section firstly decreases gradually with the expansion distance and reach a minimum distance of $74 \mathrm{~mm}$ from the center point of $0.93 \mathrm{~mm}$, whose rate of thinning was $22.5 \%$, then gradually increases and also reaches the maximum at the flange of $1.51 \mathrm{~mm}$. The above simulation results explains that $2 \mathrm{~A} 12$ aluminum alloy fairing forming by hot stamping is a plastic forming process of local thinning and flange thickening. 

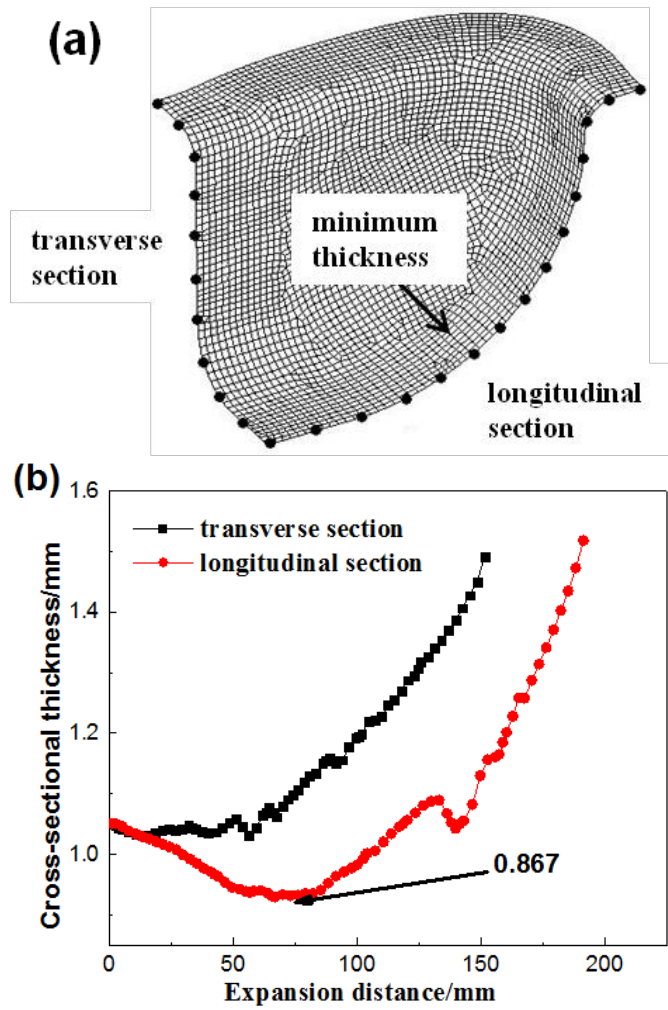

(a) Overall thickness distribution of the formed component

(b) The thickness distribution of each section

Fig.4. Overall thickness distribution of the formed component and the thickness distribution of each section

\subsection{Effect of Initial Temperature on Forming}

The forming temperature influences significantly on the plasticity of 2A12 hard aluminum alloy. With the increases of forming temperature, the forming limit is higher and the plasticity is better during thermoforming. However, the deformation resistance is decreases simultaneously, which leads to the increased risk of rupture of the component. The extreme final temperature and the maximum thinning rate of the formed component are shown in Fig.5 (a) and (b) respectively with the change of initial forming temperature of $350{ }^{\circ} \mathrm{C}, 400{ }^{\circ} \mathrm{C}$, $450{ }^{\circ} \mathrm{C}$, while the drawing speed is $100 \mathrm{~mm} \cdot \mathrm{s}^{-1}$, blank holder force is $10 \mathrm{KN}$, die gap is $1.3 \mathrm{~mm}$ and dwell time is $6 \mathrm{~s}$ remain unchanged.

As can be seen from Fig. 5 (a), the minimum final temperature of the sheet is $307.6{ }^{\circ} \mathrm{C}, 355.7{ }^{\circ} \mathrm{C}$ and $402.6{ }^{\circ} \mathrm{C}$, respectively, and the maximum cooling rate is $42.4{ }^{\circ} \mathrm{C} \cdot \mathrm{s}^{-1}$ and $44.3{ }^{\circ} \mathrm{C} \cdot \mathrm{s}^{-1}, 47.4{ }^{\circ} \mathrm{C} \cdot \mathrm{s}^{-1}$, respectively. It is reported that the maximum cooling rate of the sheet is higher than $38{ }^{\circ} \mathrm{C} \cdot \mathrm{s}^{-1}$, which can inhibit the change of percipitation [17]. Fig. 5 (b) shows that the maximum thinning rate of the sheet increases slightly with the increasement of the forming temperature. While the forming temperature increases from $350{ }^{\circ} \mathrm{C}$ to $450{ }^{\circ} \mathrm{C}$, the maximum thinning rate increases from $26.83 \%$ to $28.42 \%$, with a difference of $1.59 \%$, indicating that the change of forming temperature within $350{ }^{\circ} \mathrm{C} \sim 450{ }^{\circ} \mathrm{C}$ has little effect on the maximum thinning rate of the hot stamping process of the studied fairing. Taking into account the loss of temperature in the sheet transfer from the heating furnace to the mould, and the higher the minimum final temperature, the faster the cooling speed in the quenching stage, the more able to improve the quality of the formed component, so the suitable forming temperature is $450{ }^{\circ} \mathrm{C}$.
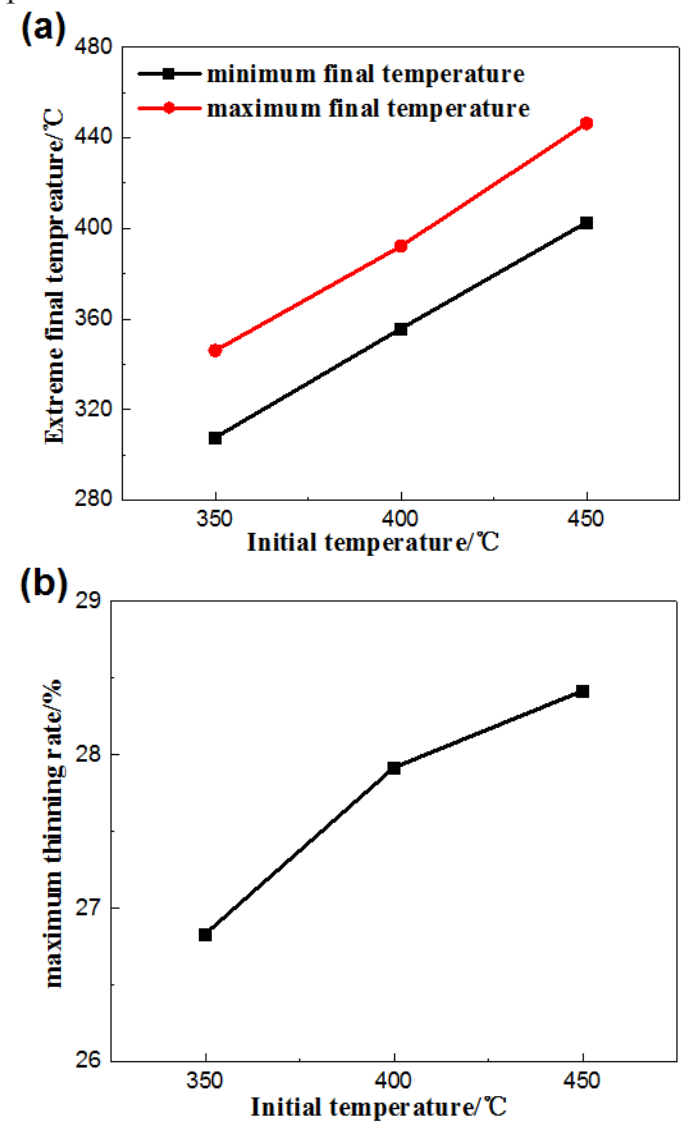

(a) The extreme final temperature with the change of initial forming temperature (b) The maximum thinning rate with the change of initial forming temperature

Fig.5. Effect of different initial temperature on the extreme final temperature and the maximum thinning rate

\subsection{Effect of BHF on Forming}

The selection of blank holder force is very important for the stamping forming process, unreasonable blank holder force will lead to wrinkling or rupture.The extreme final temperature and the maximum thinning rate of the formed component are respectively shown in Fig.6 (a) and (b) with the change of blank holder force of $6 \mathrm{KN}$, $8 \mathrm{KN}, 10 \mathrm{KN}, 12 \mathrm{KN}$, while the stamping speed is $100 \mathrm{~mm}$ - $\mathrm{s}^{-1}$, the initial forming temperature is $450{ }^{\circ} \mathrm{C}$, die gap is $1.3 \mathrm{~mm}$ and dwell time is $6 \mathrm{~s}$ remain unchanged.

As can be seen from Fig.6 (a), the extreme final temperature hardly changes with the blank holder force. This is because only the gap factor is taken into account in the definition of contact model to simplify the calculation, result in the same extreme final temperature under different blank holder force. Fig.6(b) indicate that the maximum thinning rate of the formed component increases as the blank holder force increases. When the blank holder force is $6 \mathrm{KN}, 8 \mathrm{KN}$ and $10 \mathrm{KN}$, the 
maximum thinning rates were $25.91 \%, 27.08 \%$ and $28.42 \%$, respectively. However, the maximum thinning rate exceed $30 \%$ when the blank holder force was $12 \mathrm{KN}$, which indicated the occurrence of rupture failure occurred. On the contrary, in order to avoid the wrinkling problems caused by small blank holder force, $10 \mathrm{KN}$ should be a reasonable value.
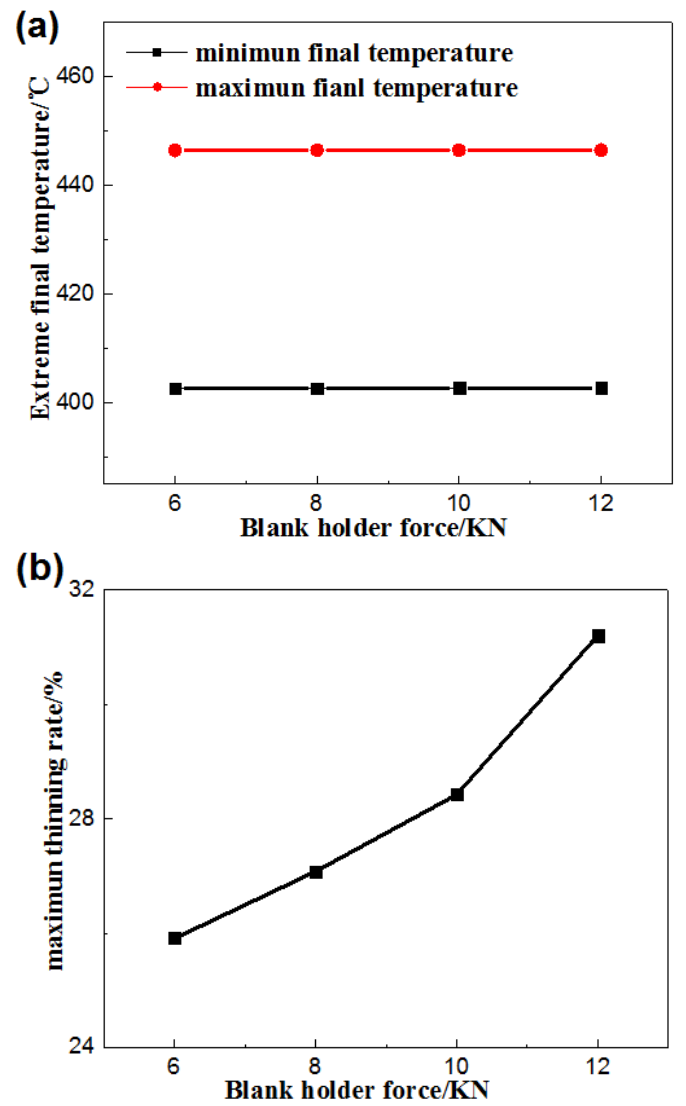

(a) The extreme final temperature with the change of BHF

(b) Tthe maximum thinning rate with the change of BHF

Fig.6. Effect of different BHF on the extreme final temperature and the maximum thinning rate

\subsection{Effect of stamping speed on Forming}

Stamping speed is as well an important process parameter in hot stamping for it not only determines the strain rate of sheet material, but also affects the distribution of temperature field of the sheet, thus affects its plasticity. The extreme final temperature and the maximum thinning rate of the component are respectively shown in Fig.7 (a) and (b) with the change of stamping speed of $60 \mathrm{~mm} \cdot \mathrm{s}^{-1}, 100 \mathrm{~mm} \cdot \mathrm{s}^{-1}, 140 \mathrm{~mm} \cdot \mathrm{s}^{-}$ ${ }^{1}, 180 \mathrm{~mm} \cdot \mathrm{s}^{-1}$, while the blank holding force is $10 \mathrm{KN}$, the initial forming temperature is $450{ }^{\circ} \mathrm{C}$, die gap is $1.3 \mathrm{~mm}$ and dwell time is $6 \mathrm{~s}$ remain unchanged.

As can be seen from Fig. 7 (a), as the stamping speed increases, the extreme final temperature of the fairing increases and the difference between maximum and minimum temperatures decreases. When the stamping speed is $60 \mathrm{~mm} \cdot \mathrm{s}^{-1}$ and $180 \mathrm{~mm} \cdot \mathrm{s}^{-1}$, the minimum temperatures are $362.96{ }^{\circ} \mathrm{C}$ and $421.21{ }^{\circ} \mathrm{C}$ respectively, the maximum temperatures are $434.8{ }^{\circ} \mathrm{C}$ and $448.92{ }^{\circ} \mathrm{C}$ respectively. This is because the contact time between the sheet and the mould is shortened with the increases of stamping speed, so the temperature distribution of the sheet is more even. From Figure 7 (b), it can be seen that the maximum thinning rate increases with the increasement of stamping speed, and when the stamping speed is over $100 \mathrm{~mm} \cdot \mathrm{s}^{-1}$, the rupture failure occurred. So for the hot stamping of larger aspect ratio of complex duralumin alloy component, stamping speed is needed to control within a certain range. In summary, combined with the extreme final temperature and thickness changes of the components, the process requirements are satisfied when the stamping speed is $100 \mathrm{~mm} \cdot \mathrm{s}^{-1}$.
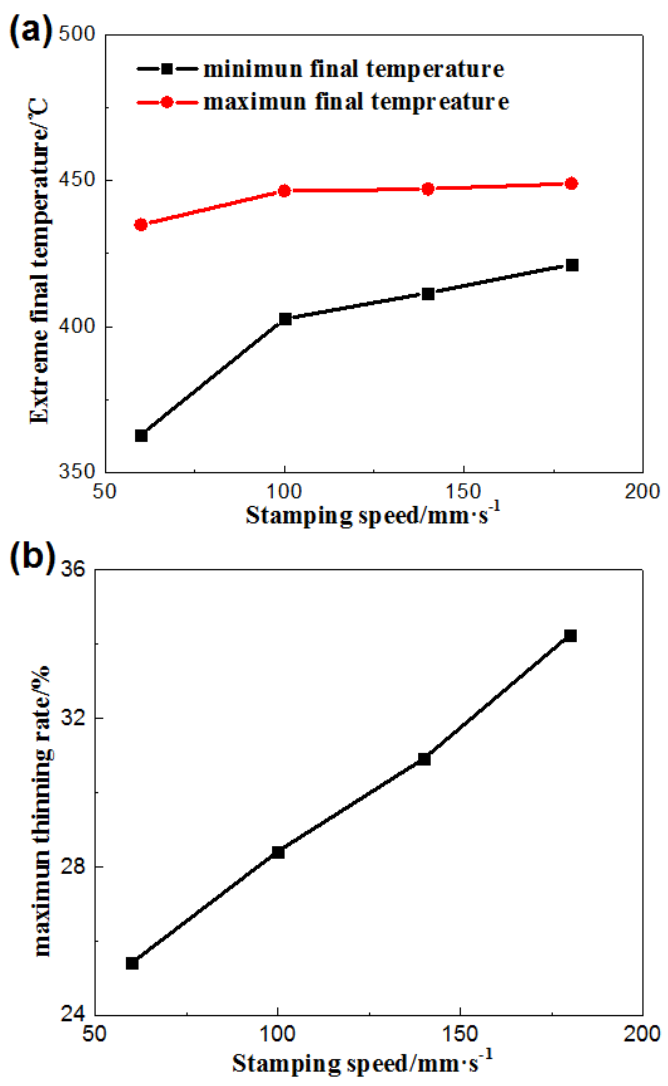

(a) The extreme final temperature with the change of drawing speed (b) The maximum thinning rate with the change of drawing speed

Fig.7. Effect of different drawing speed on the extreme final temperature and the maximum thinning rate

\section{Experimental research and analysis}

\subsection{Experimental Research on the Compound Process of 2A12 DurAlumin Alloy}

A self-design mould is developed, which shown in Fig.8, to verify the accuracy of the finite element model. And then the hot stamping of fairing experiment was carried out under the parameters that obtained by previous simulation as follows: forming initial temperature of $450{ }^{\circ} \mathrm{C}$, mould initial temperature of $25^{\circ} \mathrm{C}$, blank holder force of $10 \mathrm{KN}$, stamping speed of $100 \mathrm{~mm} \cdot \mathrm{s}^{-1}$, die gap of $1.3 \mathrm{~mm}$ and dwell time of $6 \mathrm{~s}$. 
The hot stamping process of the aluminum alloy sheet is shown in Fig. 9, the hot stamping mould was firstly installed on a hydraulic press, and then the blank was heated in a heat furnace to a given temperature for a certain time before transferred to the mould and implement the hot stamping. After quenching, the pressure was discharged and the formed component was taken out, as shown in Fig.10, which contains two fairing members.
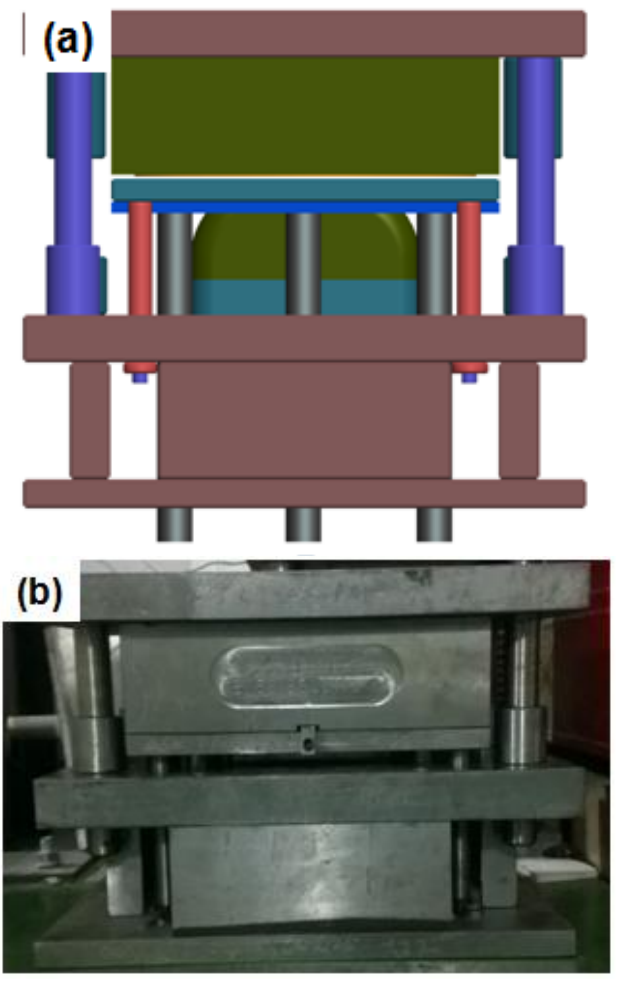

(a) 3-D map of the mould (b) Physical map of the mould

Fig.8. Structure of the self-design mould

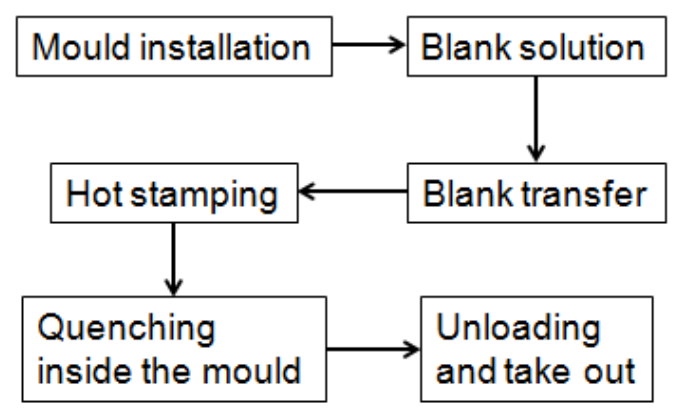

Fig.9. The process of hot drawing

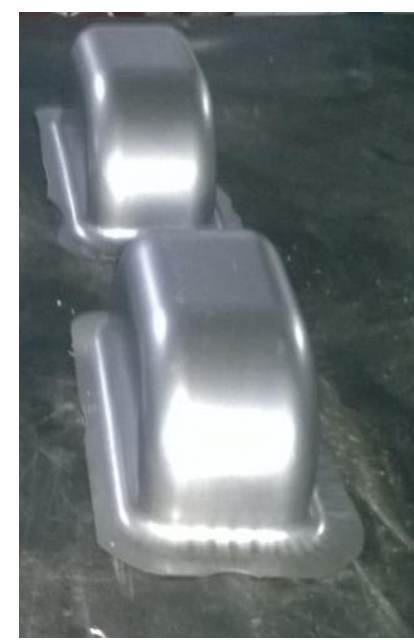

Fig.10. The formed fairing fabricated by hot stamping

\subsection{Comparison and Analysis of experiment and simulation of formed fairing thickness}

In order to obtain the thickness distribution of the fairing, the formed component was cut from the transverse and longitudinal symmetry plane, as shown in Fig.11.

The cross-sectional thickness of the above 1/4 part along the horizontal and vertical paths were measured by micrometer to compared with the finite element simulation results under the same process parameter. Comparison result in Fig. 12 shows that the simulation values of the thickness agrees well with the experimental values along the expansion path, and the maximum deviation does not exceed $3.6 \%$, which also proves the reliability of the finite element simulation.
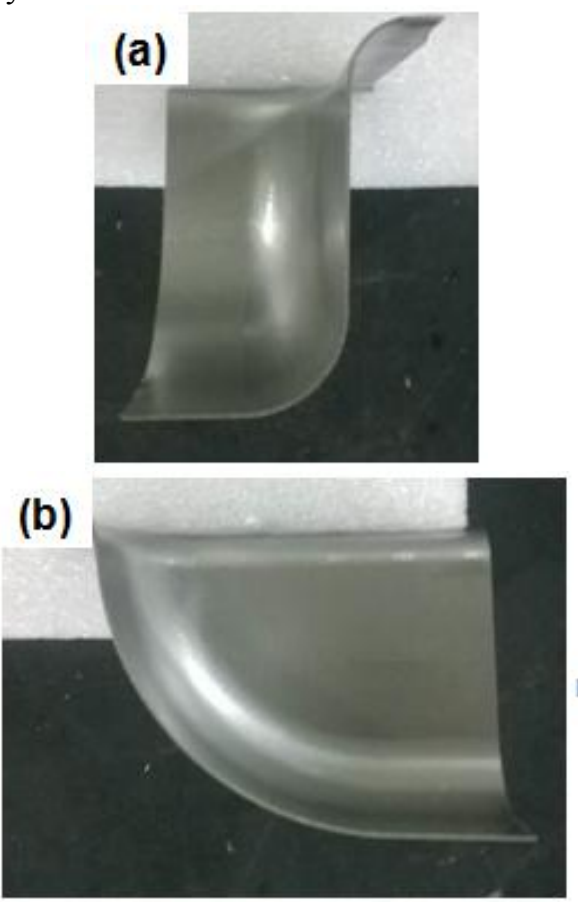

Fig.11. The quarter formed fairing(transverse and longitudinal cross-section) 

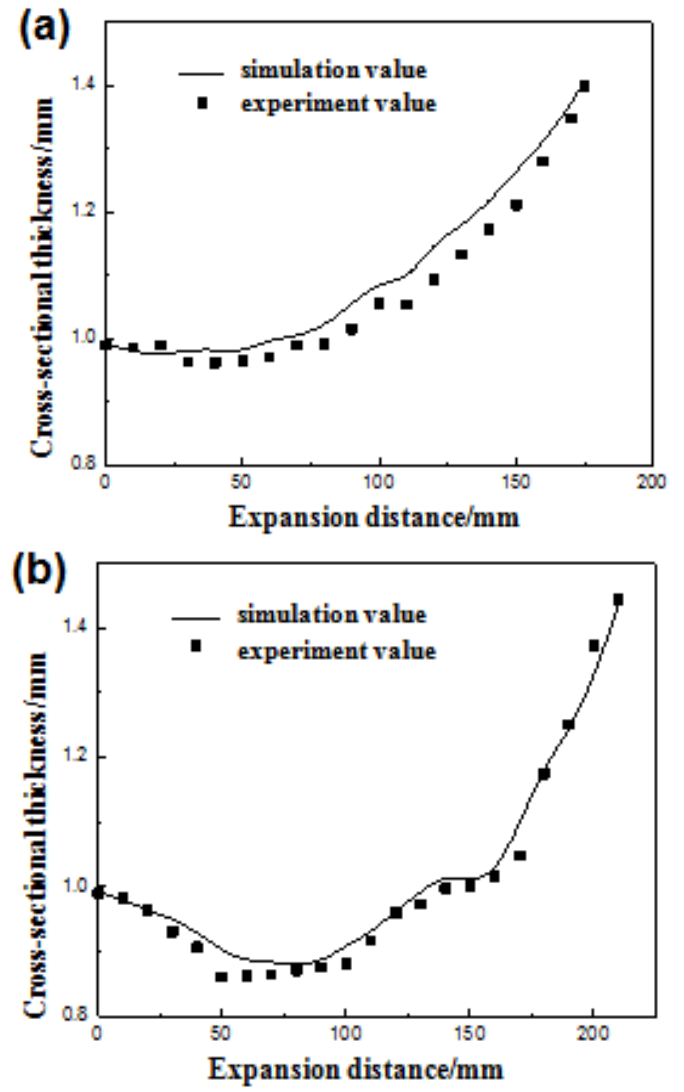

(a) Horizontal cross-section

(b) Vertical cross-section

Fig.12. The thickness value of experiment and simulation on horizontal and vertical cross-section

\section{Mechanical properties of formed fairing}

In order to test the preformance of the fairings formed by the studied process, the components were subjected to natural aging treatment (for 4 days or more at room temperature) after the compound process, and then room temperature tensile test and micro-hardness test were carried out to obtain its tensile strength, yield strength, elongation and micro-hardness. The tensile test specimens with a parallel length of $25 \mathrm{~mm}$ and a width of $10 \mathrm{~mm}$ were taken from the corresponding positions of the components by wire cutting and the size is shown in .

\subsection{Tensile mechanical properties of the formed fairing}

The tensile strength, yield strength and elongation results at room temperature of the sidewall and the bottom of the fairing are listed in Table 2. As can be seen from the table, there is a certain difference in the strength and plasticity between the sidewalls and the bottom of the formed fairing, but the deviation is small. In addition, comparison of the properties of the hot stamping parts with the properties of the sheet after trandition solutionquenching-natural aging heat-treated shows that the hot stamping parts can still meet the strength and plasticity requirements.

Table 2. Tensile mechanical properties of the sidewall and the bottom of the formed fairing

\begin{tabular}{cccc}
\hline Type & $\begin{array}{c}\text { Tensile } \\
\text { strength /MPa }\end{array}$ & $\begin{array}{c}\text { Yield strength } \\
\text { /MPa }\end{array}$ & $\begin{array}{c}\text { Elongati } \\
\text { on/\% }\end{array}$ \\
\hline $\begin{array}{l}\text { 2A12-T4 sheet } \\
\text { Sidewall of the } \\
\text { formed fairing } \\
\text { bottom of the } \\
\text { formed fairing }\end{array}$ & 474 & 327 & 11.8 \\
\hline
\end{tabular}

\subsection{Micro-hardness of the formed fairing}

Vickers micro-hardness test was carried out for 4 position, namely the flange(A), sidewall(B), bottom(C) and rounded(D), of the formed fairing as shown in Fig.13. Three fairing parts, labeled \# 1, \# 2, \# 3, were tested for average value, and the results are shown in Table 3.

It can be found from the table that there is a certain difference of micro-hardness between the 4 positions. According to the simulation result above, those 4 parts of the sheet suffered from different temperature and stress state during the whole hot stamping stage, result in the differences in micro-hardness. But the maximum deviation of the average micro-hardness value of the various position is within $8 \%$, which meet the quality requirements of the parts. Additionally, the microhardness of all the three fairing in the same position have the maximum deviation of only $1.9 \%$, indicating that the experiment has good repeatability.

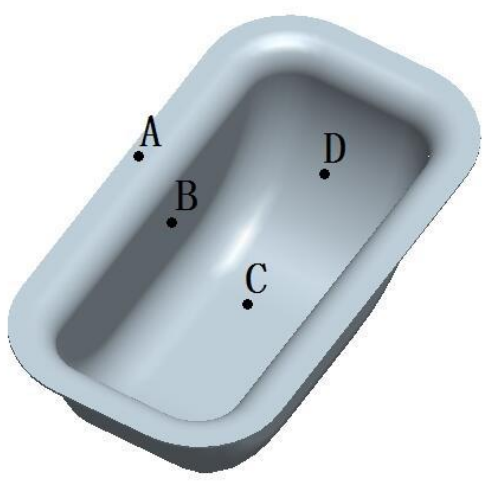

Fig.13. Position of A, B, C and D 
Table 3. Micro-hardness of the formed fairing in A, B, C and $\mathrm{D}(\mathrm{HV})$

\begin{tabular}{ccccc}
\hline Position & $\# 1$ & $\# 2$ & $\# 3$ & $\begin{array}{c}\text { Average } \\
\text { valus }\end{array}$ \\
\hline A & 134.3 & 133.7 & 136.2 & 134.7 \\
B & 132.5 & 133.1 & 133.6 & 133.1 \\
C & 128.8 & 129.9 & 130.2 & 129.6 \\
D & 124.6 & 124.1 & 124.3 & 124.3 \\
\hline
\end{tabular}

\section{Conclusion}

(1) A finite element model was established by using MARC software to optimize the shape of blank and to study the influences of initial forming temperature, blank holder force and stamping speed on temperature and thickness distribution systematically during the fairing hot stamping process, which help to determine the process parameters on the subsequent experiments. (2) The reliability of finite element simulation was proved by the hot stamping experiments with selfdesigned moulds. Compared with the component thickness of the stamping trial and numerical simulation, the deviation was less than $3.6 \%$.

(3) Mechanical properties and micro-hardness at room temperature of the formed fairing were tested, the results show that the hot stamping fairing can meet the strength and plasticity requirements, as well has good repeatability.

\section{Acknowledgements}

This research was supported by the National Natural Science Foundation of Hunan Province (Grant No. 13JJ2009)

\section{References}

1. J.Z. Cao, Z.T. Wang. L. A. F. Tech, 4, 1-12, 2013

2. X.F. Xu, G.Q. Tong. J. Plast. E 16, 64-68, 2009

3. B.F. Song. Aerospace Technology Introduction. National Defense Industry Press. 2006

4. H.J. McQueen, J.J. Jonas. Trea. Mater. Sci. Tech. 6, 394, 1971

5. P.F. Variani, S Bruschi, A Ghiotti, et al. CIRP A-M Tech. 62, 251-254, 2013

6. S. Yoshihara, H. Nishimura, H. Yamamoto, et al. J. M. P. T. 142, 609-613, 2003

7. D.M. Finch, S.P. Wilson, J.E. Dom. Trans. ASM. 36, 254-289, 1946

8. M.J. Painter, R. Pearce. A. American Society for Testing and Materials, Formability of Metallic Materials-2000 AD, Special Technical Publications. 105-118, 1982

9. Z.H. Guo, Z.G. Li, K.J. Ouyang, X.H. Dong. Developing R. China Metal. Equi. Manu. Tech. 38, 80-82, 2003
10. L. Fu, B.Y. Wang, Q.L. Meng, et al. J. CSU(Sci. Tech.) 3, 936-941, 2013

11. J. Zhou, B.Y. Wang, J.G. Lin, L. Fu. ARCH. CIV. MECH. ENG. 13, 401-411, 2013

12. J. Zhou, B.Y. Wang, J.G. Lin, L. Fu. Trans. Nonferrous Met. Soc. China. 24, 2014

13. M.S. Mohamed, A.D. Foster, J. Lin, D.S. Balint, T.A. Dean. INT J MACH TOOL MANU. 53, 27-38, 2012

14. W.K. Li, L.H. Zhan, J. Zhao. CHIN J NONFERROUS MET. 26, 1159-1166. 2016

15. A.D. Foster, T.A. Dean and J Lin, Priority Date: 19 Sept. 2008, Process for forming aluminium alloy sheet component, International Publication No.: WO2010/032002 A1

16. A.D. Foster, M. Mohamed, J. Lin, et al. Steel Res Int, 79, 133-140, 2008

17. H.Y. Li, J. Bin, X.F. Wang, Y. Tang. CHIN J NONFERROUS MET. 21, 2068-2074, 2011 